the sun with reference to the planet. Owing to the comparatively large eccentricity of the orbit of Mercury, perihelion and aphelion conjunctions are dealt with separately, and the material was reduced to those conjunctions for which the most outstanding effects would be expected: these are at inferior conjunction when both the earth and Mercury are in perihelion; and at superior conjunction when Mercury is close to perihelion and the earth to aphelion. Next, the results were analysed for the least favourable conditions, that is, when Mercury is in aphelion and the earth also in aphelion at inferior conjunction and when Mercury is in aphelion and the earth in perihelion at superior conjunction. The results are shown by a number of curves, but the correlation between the sunspot-characteristic and the synodic revolution of Mercury is not so well defined as in the case of Venus. It is suggested that this may be due to the large eccentricity of Mercury's orbit, which makes the statistical results more difficult, or to a smaller hypothetical influence of Mercury. Nevertheless, analogical forms of the curves of sunspot-characteristics for Mercury as for Venus have been obtained, and it is possible to assume that Mercury has an influence in the production of sunspots.

\section{Rock Engravings in the Kilimanjaro Area}

IN the November and December numbers of Man there is an important article by H. A. Fosbrooke, sen., a sociologist of Tanganyika Territory, and Petro I. Marealle, chief of the Vungo division of the Chagga tribe, on the engraved rocks of Kilimanjaro and their meaning and use in initiation ceremonies. Rocks covered with apparently meaningless engraved lines are known from many parts of Africa. It is not suggested that the explanation given for the ones of Kilimanjaro applies in all cases ; but it may well be that the others were used for some analogous purposes. In the November number, Fosbrooke describes the engraved rocks and supplies a couple of pages of excellent illustrations. In the December number, Marealle describes the use and explanation. "From the body of the youths of the age set are chosen 12 who are the children of people of importance. . . . The stone itself is engraved thus. The elder who is the instructor goes with the 12 youths to the stone. He wears a ring of hide, and says to them 'you see this stone and its engravings : look this is your whole country. The youths of old who made these marks were led by an elder who like myself knew much wisdom'. . . Then the elder gives one of the 12 a little axe and shows him how to cut a line on the stone. The youth cuts a small mark from two to six inches long." Thus the rocks become more and more covered with engraved lines apparently meaningless. The ceremony, of course, continues, but enough has been quoted to give the gist of the explanation. 'I'his seems to be the first time such an account of such a ceremony and of the reason why these rocks get covered with engraved lines has ever been given; and it is factual, given by a man who formerly was an instructor, and is not an explanation produced out of the fancy of a psychological anthropologist.

\section{High-frequency Electric and Magnetic Shielding}

THE third monograph of the series issued by the Research Institute of Applied Electricity, Hokkaido University, Sapporo, Japan, is entitled "Some Researches on High-Frequency Phenomena and Electrical Direct Heating" (Monograph Series No. 3; pp. 105; 1952) and contains four papers, two of which deal with the important problem of electrical shielding of high-frequency apparatus. In the first of these, Y. Asami, the director of the Institute and editor of the monograph series, and A. Matsumoto discuss in general terms the various sources and methods of suppression of electromagnetic leakage in high-frequency apparatus and then consider theoretically the principles of electric and magnetic shielding. They follow this by a description of a number of experiments performed with special care to detect the defects of apparatus made in Japan, and it is concluded that radio interference from high-frequency apparatus can be almost eliminated by application of the suggestions made. It is emphasized that, as some kinds of wire nettings used for screening are subject to rapid deterioration, good netting resistant to deterioration must be selected and used. The second paper, by T. Matsumoto, is a continuation of the one, on the theory of electromagnetic shielding by a shielding room of wire-netting, which appeared in No. 1 of the series. Several fresh problems are briefly considered: the effects of finite dimensions of the current-loop wave source, and of the eccentricity of its position relative to the centre of the shielding room; and the theories of double shielding formed by two concentric spherical walls of wirenetting, and of shielding by a shielding room consisting of a cylindrical cavity with perfectly conducting walls and with a wire-netting bottom.

\section{Seasonal Variation in the Reproductive System of Garter Snakes}

Axthough many papers have been written, there is still much that is not understood concerning the external and internal factors responsible for the cyclic nature of reproduction in reptiles. Investigations of the seasonal fluctuations in various parts of the reproductive system of several species of lizards, snakes and turtles have revealed interesting species differences. For a more complete understanding of reptilian reproduction it would appear that detailed descriptions of the seasonal changes of many species are desirable ( $J$. Morph., 90, No. 3; May 1952). Such a study was carried out by Wade Fox on the common garter snake (Thamnophis), several species and subspecies of which could easily be obtained throughout the year in the vicinity of San Francisco Bay. These investigations showed that the gonads of the male garter snake, Thamnophis elegans terrestris, exhibit marked seasonal variation. The testes begin to increase in size in the early spring, reach their maximum size and weight in late July, decline in the autumn, and are of minimum size during the winter months. These macroscopic fluctuations are accompanied by corresponding histological changes.

\section{Collections of British Birds and Eggs}

IN the March number of the Museums Journal Mr. Colin Matheson (National Museum of Wales) has performed a useful service in that he has collated much information regarding the present location of museum collections of British birds and eggs. In order to add to the value of such notes, he has included collections which are known to have been destroyed during the Second World War. Changes in outlook, as well as in economic and social conditions, make it unlikely that many more large collections will be formed, and hence it is important that ornithologists should know the whereabouts of the material available for study. 